\begin{tabular}{|c|c|}
\hline Title & Dynamics of Photoelectrons and Structural Changes of T ungsten Trioxide Observed by Femtosecond Transient X AFS \\
\hline Author(s) & $\begin{array}{l}\text { Uemura, Y ohei; Kido, Daiki; Wakisaka, Y uki; U ehara, Hiromitsu; Ohba, T adashi; Niwa, Y asuhiro; Nozawa, Shunsuke; } \\
\text { Sato, T okushi; I chiyanagi, Kohei; Fukaya, Ryo; A dachi, Shin-ichi; Katayama, T etsuo; Togashi, T adashi; Owada, } \\
\text { Sigeki; Ogawa, Kanade; Y abashi, Makina; Hatada, Keisuke; T akakusagi, Satoru; Y okoyama, T oshihiko; Ohtani, } \\
\text { Bunsho; A sakura, Kiyotaka }\end{array}$ \\
\hline Citation & $\begin{array}{l}\text { A ngewandte Chemie International edition, 55(4), 1364-1367 } \\
\text { https://doi.org/10.1002/anie.201509252 }\end{array}$ \\
\hline Issue Date & 2016-01-22 \\
\hline Doc URL & http:/hdl.handle.net/2115/64238 \\
\hline Rights & $\begin{array}{l}\text { This is the peer reviewed version of the following article: A ngewandte Chemie International edition, January } 22 \\
\text { V ol.55(4) } 2016 \text { pp. 1364-1367, which has been published in final form at } \\
\text { http://onlinelibrary.wiley.com/doi/10.1002/anie.201509252/abstract.This article may be used for non-commercial } \\
\text { purposes in accordance with Wiley T erms and Conditions for Self-A rchiving. }\end{array}$ \\
\hline Type & article (author version) \\
\hline Additional Information & There are other files related to this item in HUSCA P. Check the above URL. \\
\hline File Information & W03_A ngewandte_SI_revised_20151031.pdf (Supporting information) \\
\hline
\end{tabular}

Instructions for use 


\section{Dynamics of photoelectrons and structural changes of tungsten trioxide observed by femtosecond transient XAFS}

Yohei Uemura ${ }^{\mathrm{a}}$, Daiki Kido ${ }^{\mathrm{b}}$, Yuki Wakisaka ${ }^{\mathrm{a}, \mathrm{c}}$, Hiromitsu Uehara ${ }^{\mathrm{b}}$, Tadashi Ohba ${ }^{\mathrm{b}}$, Yasuhiro Niwa ${ }^{d}$, Shunsuke Nozawa ${ }^{d}$, Tokushi Sato ${ }^{d}$, Kohei Ichiyanagi ${ }^{d}$, Ryo Fukaya ${ }^{d}$, Shin-ichi Adachi ${ }^{\mathrm{d}}$, Tetsuo Katayama ${ }^{e}$, Tadashi Togashi ${ }^{\mathrm{e}}$, Sigeki Owada ${ }^{\mathrm{f}}$, Kanade Ogawa ${ }^{f}$, Makina Yabashi ${ }^{\prime}$, Keisuke Hatada ${ }^{g}$, Satoru Takakusagi ${ }^{b}$, Toshihiko Yokoyama ${ }^{a}$, Bunsho Ohtani $^{\mathrm{b}}$, Kiyotaka Asakura ${ }^{\mathrm{b} *}$

Index

1. $\mathrm{W} \mathrm{L}_{\mathrm{III}} \mathrm{XANES}$ of $\mathrm{WO}_{3}$ and $\mathrm{WO}_{2}$ and their first derivatives.

2. $\mathrm{WO}_{3}$ spectrum and its derivatives in the ground state.

3. The XANES calculations for orthorhombic and monoclinic structures.

4. Valence states of photoexcited $\mathrm{WO}_{3}$ species. 
1. $\mathrm{W} \mathrm{L}_{\mathrm{III}} \mathrm{XANES}$ of $\mathrm{WO}_{3}$ and $\mathrm{WO}_{2}$.

Figure $\mathrm{S} 1$ shows the $\mathrm{WL}_{\mathrm{III}}$ edge XANES of $\mathrm{WO}_{3}$ and $\mathrm{WO}_{2}$. The broad peak in the raw data, known as a "white line," corresponds to the dipole transition from the $2 \mathrm{p}_{3 / 2}$ to the $5 \mathrm{~d}$ state. The white line peak area is normally proportional to the empty $d$ state and so is a good indicator of the number of empty d states. Here the white line peak intensity is reduced because of filling of the d orbitals. An edge shift to a lower energy is also observed in the case of the $\mathrm{WO}_{2}$.

(a)

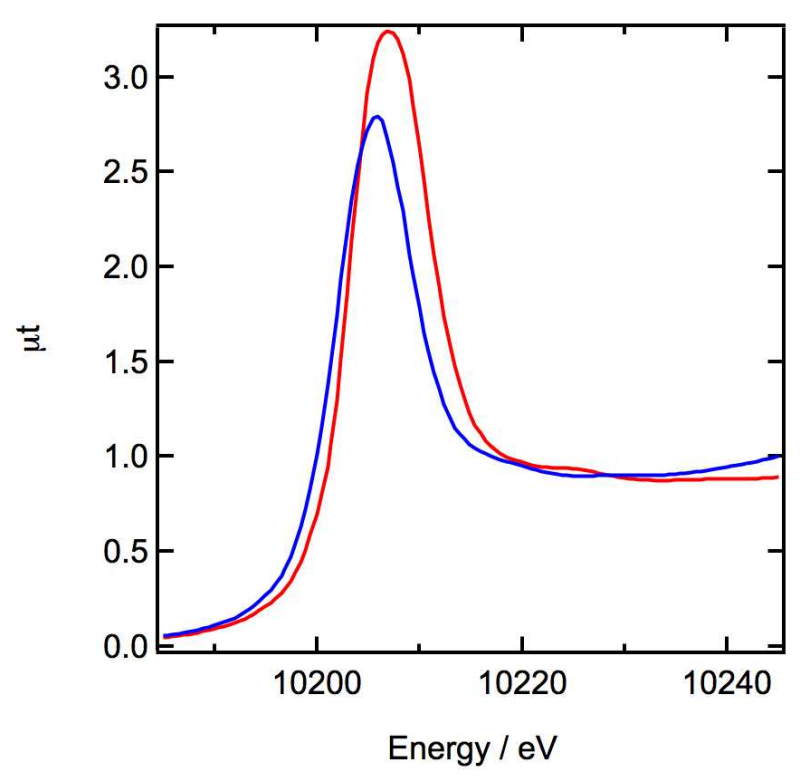

(b)

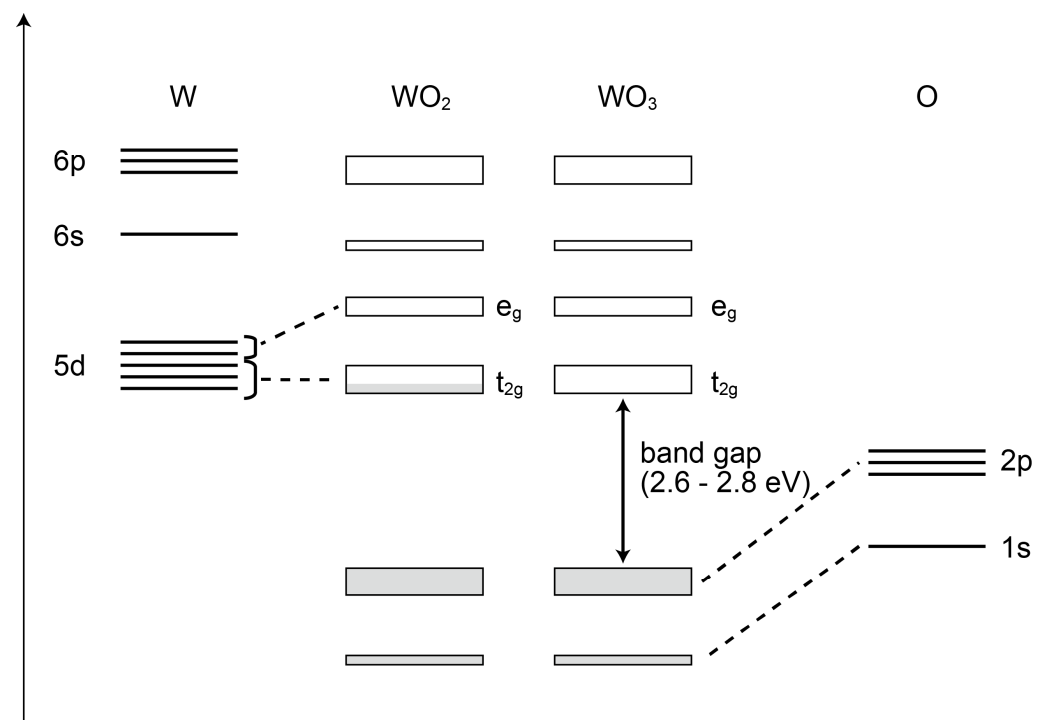

Figure $\mathrm{S} 1$ (a) $\mathrm{W} \mathrm{L}_{\text {III }}$ XANES of $\mathrm{WO}_{3}$ (red) and $\mathrm{WO}_{2}$ (blue). The white line peak intensity increases with higher oxidation states and the peak shifts to the higher energy side as the oxidation state increases. (b) a schematic diagram of band structures of $\mathrm{WO}_{2}$ and $\mathrm{WO}_{3}$.[1] [1] G. A. Niklasson and C. G. Granqvist J. Mater. Chem. 2007, 17, 127-156. 
2. $\mathrm{WO}_{3}$ spectrum in the ground state.

Figure $\mathrm{S} 2$ shows the $\mathrm{WO}_{3}$ spectrum together with the first and second derivatives.

The first derivative exhibits one positive peak and one negative peak. The second derivative shows two negative peaks that correspond to $d$-d splitting. Assuming that the $\mathrm{WO}_{3}$ has approximately octahedral symmetry, these two peaks can be assigned to the $t_{2 g}$ and eg orbitals.

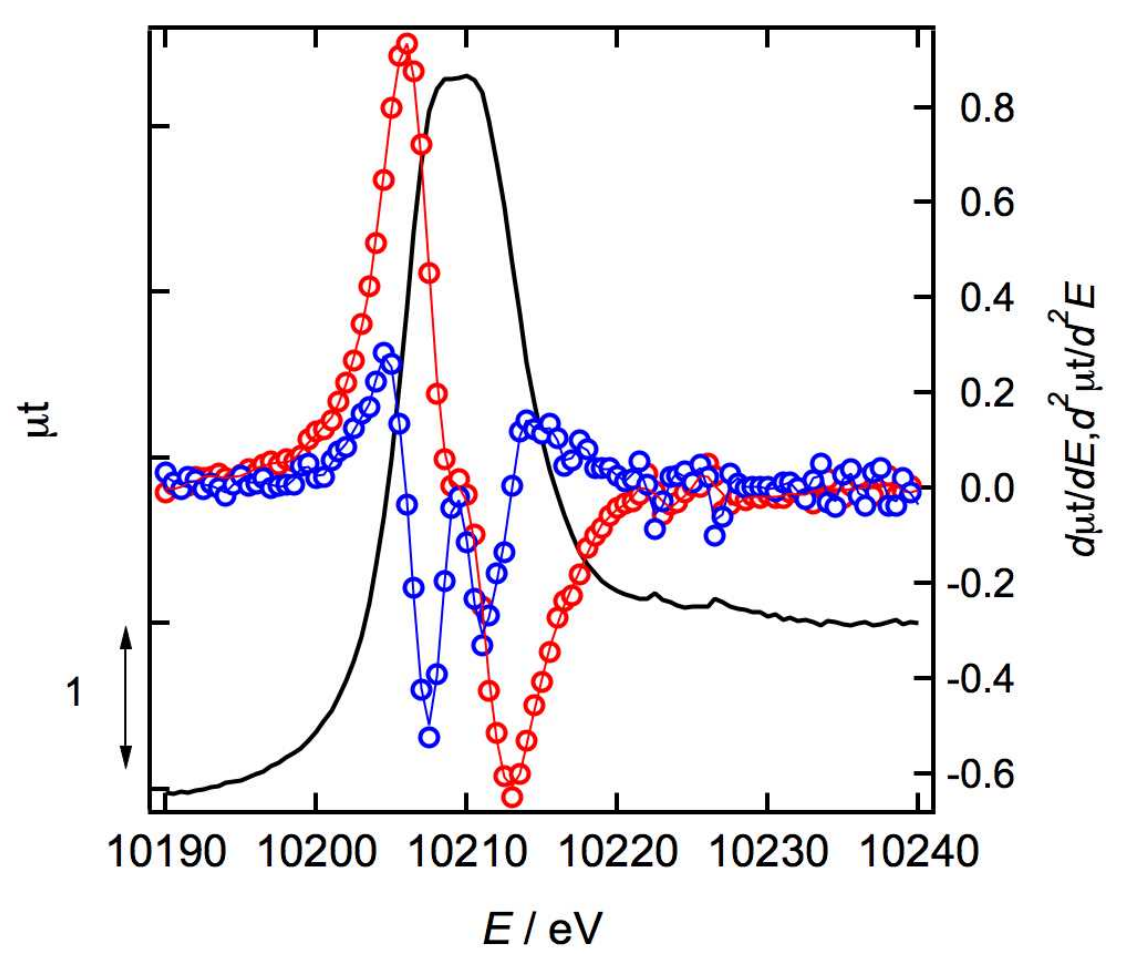

Fig. S2 W L $\mathrm{L}_{\mathrm{III}}$ XANES of $\mathrm{WO}_{3}$ together with the first and second derivatives. 
The difference spectrum of the XANES of the real $\mathrm{WO}_{3}$ and the virtual XANES of $\mathrm{WO}_{3}$ shifted to lower energy by an amount equal to $\Delta \mathrm{E}$ can be approximately written as

$$
\Delta \mu=\frac{\mathrm{d} \mu}{\mathrm{dE}} \Delta \mathrm{E}
$$

Comparing the difference spectra before and after photo-irradiation shows similar positive and negative peaks, as in Figure S3.

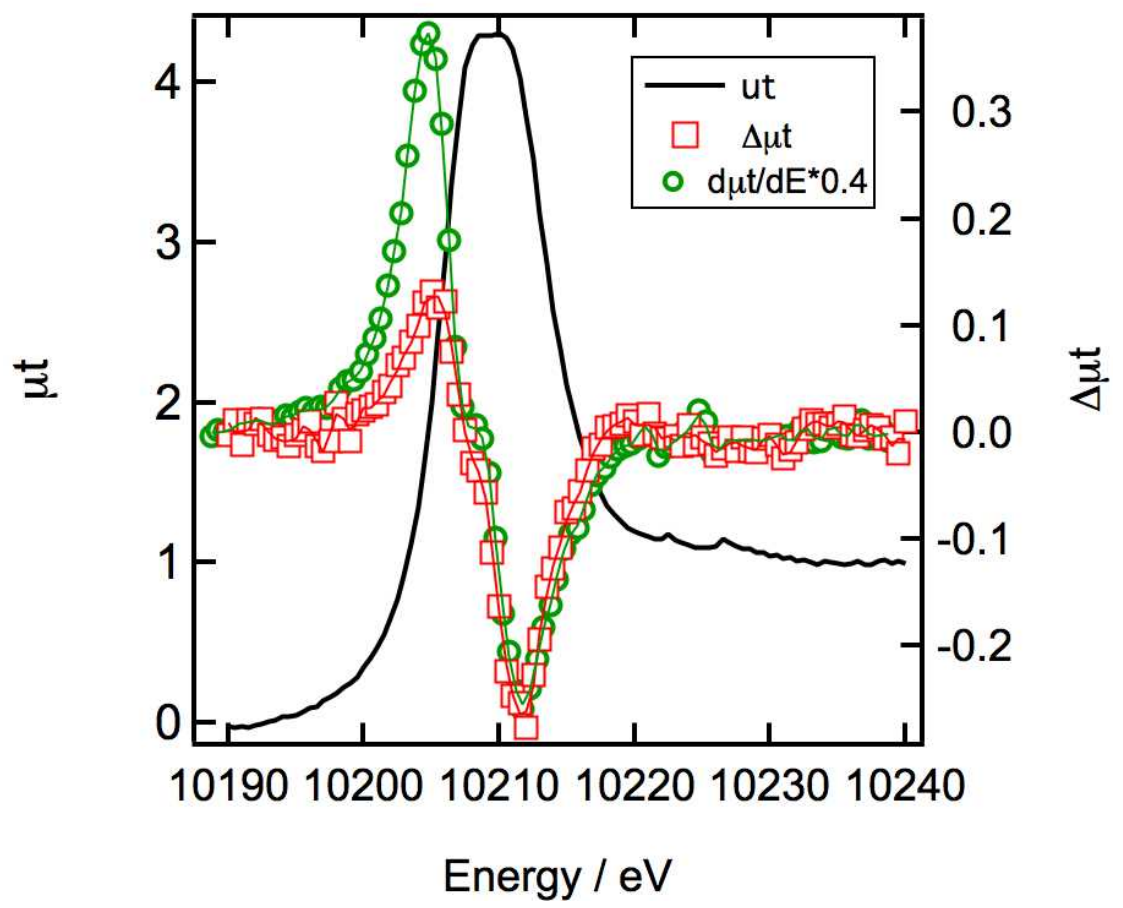

Fig. S3 W L $\mathrm{L}_{\text {III }}$ XANES $(\mu \mathrm{t})$, the difference spectrum at $0.5 \mathrm{ps}(\Delta \mu \mathrm{t})$ and the first derivative of the $W L_{\text {III }}$ XANES (d $\left.\mu \mathrm{t} / \mathrm{dE}\right)$. 
3. The XANES calculations of $\mathrm{WO}_{3}$ orthorhombic and monoclinic structures at their ground states.

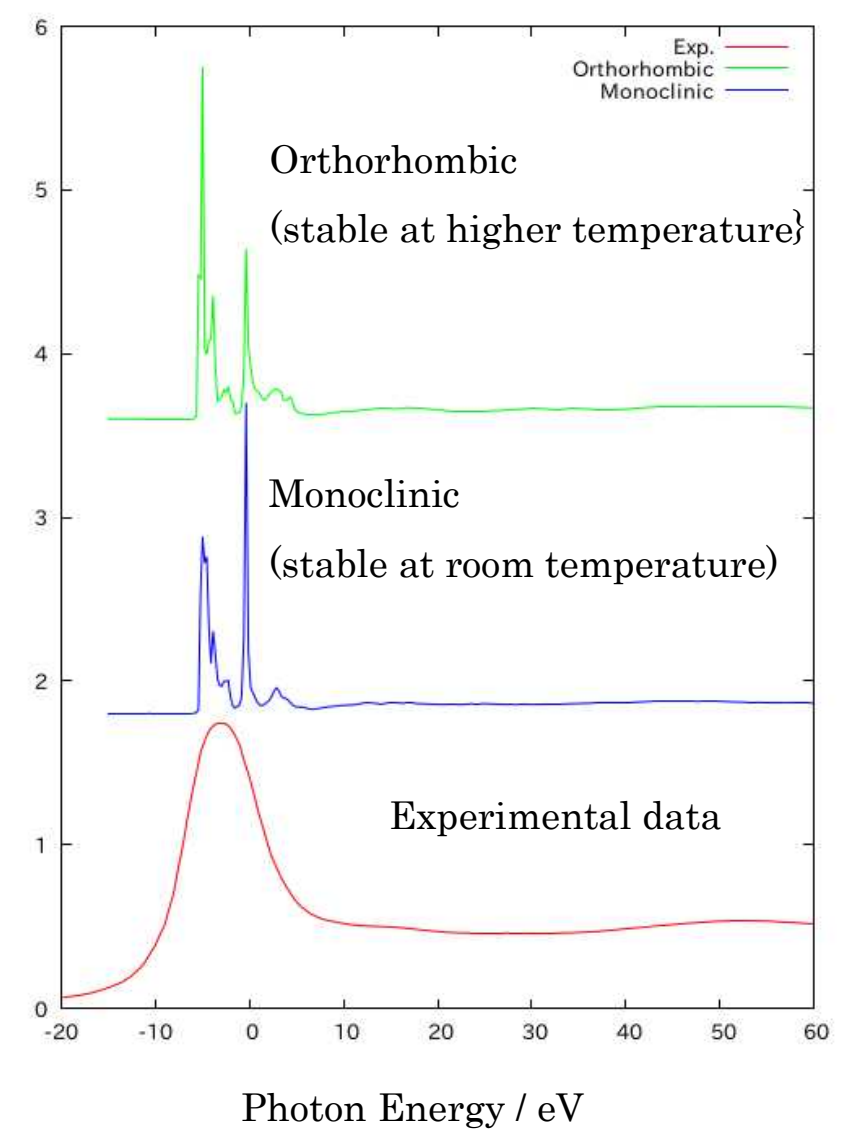

Figure S4 Calculated XANES for orthorhombic and monoclinic $\mathrm{WO}_{3}$ structures together with experimental (ground state) data.

Figure $\mathrm{S} 4$ shows the calculated XANES for orthorhombic and monoclinic $\mathrm{WO}_{3}$ structures together with experimental (ground state) data. The monoclinic structure is the room temperature structure and thus we obtained the XANES of the monoclinic structure. In contrast, the orthorhombic structure is present at high temperatures. The XANES calculations were performed using the FPMS code[2], which is based on the real space full potential multiple scattering theory beyond the muffin tin approximation with space filling cells. In these calculations, the cells were truncated to avoid overlapping and so-called "empty cells" that had charge density but no nuclei were placed in the interstitial regions. The clusters were $6 \AA$ in size and the value of $l_{\max }$ was 5 . The monoclinic structure was found to give a more intense peak in the higher energy region, while the orthorhombic structure produced stronger peaks in the lower energy region. We are currently refining the structures to obtain better fitting results. 
[2] K. Hatada, K. Hayakawa, M. Benfatto, C. R. Natoli, J. Phys.: Condens. Matter 2010, 22, 185501; K. Hatada, K. Hayakawa, M. Benfatto, C. R. Natoli, J. Phys.: Condens. Matter 2009, 21, 104206.

4. Valence states of photoexcited $\mathrm{WO}_{3}$ species.

We attempted to calculate the valence states of the photoexcited species using the white line peak areas and edge shifts. Figure S5 summarizes the white line area changes following the photoexcitation process. The original white line was observed to abruptly decrease upon photoabsorption, since the $\mathrm{d}$ state is filled with the excited electron from the $\mathrm{O}$ valence state. The white line area does not largely change up to $200 \mathrm{ps}$ and then decreases. Figure S6 shows the relationship between the valence state and the white line area ratio, calculated using the equation

$$
\text { White line area ratio }=\frac{A(\mathrm{X})}{A(\mathrm{VI})} \text {, }
$$

where $A(\mathrm{X})$ and $A(\mathrm{VI})$ are the white line areas of the $\mathrm{W}^{\mathrm{X}+}$ and $\mathrm{W}^{6+}$ species, respectively. Assuming that photoabsorption causes transitions only to the $\mathrm{d}$ state, the valence state estimated from white line area has a value of $5.2+$.

The relationship between edge shift and valence was estimated from data for the reference compounds $\mathrm{W}, \mathrm{WO}_{2}$ and $\mathrm{WO}_{3}$, and is presented in Fig. S7. The edge shift was estimated at approximately $-0.4 \mathrm{eV}$. This edge shift corresponds to a change in the valence of - 0.5 , such that the valence state of the excited $\mathrm{W}$ was estimated to be +5.5 .

Based on these results, we can safely say that the valence of $\mathrm{W}$ was in the range of 5.3 \pm 0.3 . 


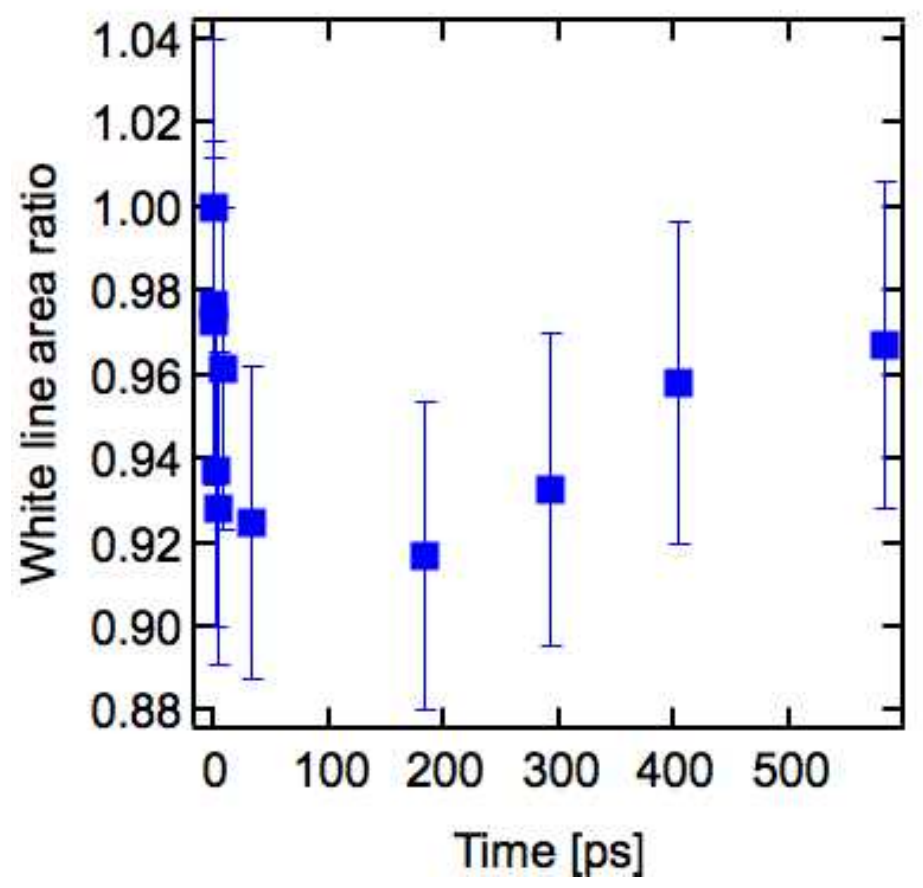

Figure S5 White line area ratio as a function of time.

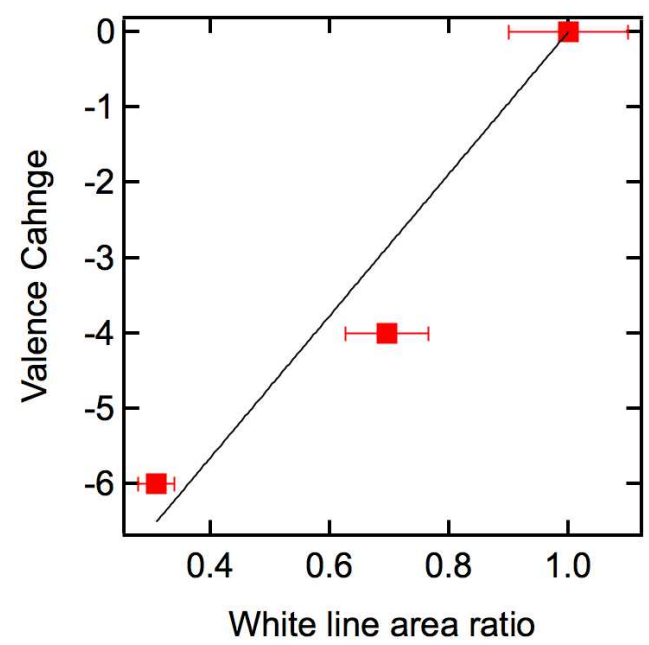

Figure S6 Valence state change of $\mathrm{W}$ compounds as a function of white line area ratio. 


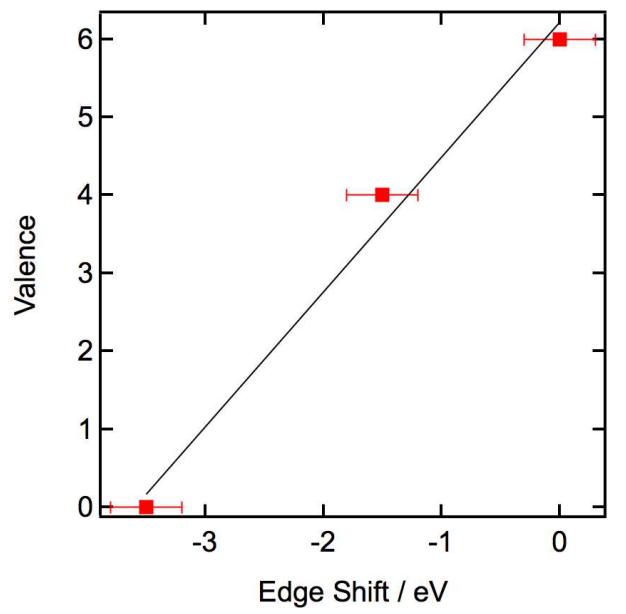

Figure S7 Valence state of reference compounds as a function of the edge shift. 